\title{
Clinical impact of High-Definition Endoscopic Ultrasonography (EUS) in a district hospital
}

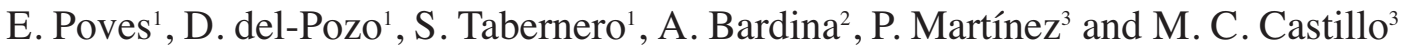 \\ ${ }^{1}$ Servicio de Aparato Digestivo. ${ }^{2}$ Servicio de Anestesia y Reanimación. ${ }^{3}$ Servicio de Anatomía Patólogica. Hospital \\ Universitario Príncipe de Asturias. Alcalá de Henares. Madrid, Spain
}

\begin{abstract} tice.

Objectives: Evaluation of the impact of EUS in clinical prac-

Methods: All explorations performed during the first 18 months of implementation of the technique were analyzed. Agreement was assessed by radiographic techniques or surgical specimens in those cases allowed.

Results: 277 explorations were performed. There have been only 2 complications and they were related to sedation in both cases. The demand increased gradually, reaching 70 scans per 100,000 inhabitants. Main indications were bile (34.3\%) and pancreatic processes. No pathology was found in 10\% of cases; 29 cases had choledocholithiasis $(93 \%$ confirmed and treated endoscopically). Chronic pancreatitis was diagnosed in 19 cases (only $15.78 \%$ of the cases were diagnosed by computed tomography). Thirty two patients with idiopathic acute pancreatitis were evaluated: 20 of them had evidence of microlithiasis $180 \%$ cholecystectomized and asymptomatic after a mean follow-up of 21.5 months), two cases of choledocholithiasis, 1 with chronic pancreatitis and 9 cases remained free of filial etiology. We performed 56 punctures: 39 samples of pancreas in 33 patients $(81.1 \%$ of the samples were diagnostic; adenocarcinoma and serous cystadenoma were the most common diagnoses), 13 enlarged nodes and 4 abdominal masses.

Conclusions: EUS is a growing demanded technique that has low risks and leads to better decision-making in a significant number of patients with different diseases. Therefore, its inclusion in routine clinical practice must be considered.
\end{abstract}

Key words: EUS. Clinical impact.

\section{RESUMEN}

Objetivos: Evaluar el impacto de la introducción de la ecoendoscopia en la práctica clínica.

Métodos: Se analizaron todas las exploraciones realizadas en los primeros 18 meses de implantación de la técnica. Se valoró la concordancia mediante técnicas radiológicas o piezas quirúrgicas en los casos en los que fue posible.

Resultados: Se realizaron 277 exploraciones. Sólo se han registrado 2 complicaciones y en ambos casos fue en relación con la sedación. La demanda fue en aumento, alcanzando 70 exploraciones/100.000 habitantes. Las indicaciones principales fueron procesos biliares $(34,3 \%)$ y pancreáticos. No se encontró patología alguna en el 10\% de los casos. 29 presentaban coledocolitiasis (93\% confirmadas y tratadas endoscópicamente). Se diagnosticaron 19 pancreatitis crónicas (sólo el 15,78\% fueron diagnosticadas por tomografía computarizada). Se evaluaron 32 pacientes con pancreatitis aguda idiopática: en 20 de ellos se visualizó microlitiasis (80\% fueron colecistectomizados y permanecen asintomáticos tras una media de seguimiento de 21,5 meses), 2 casos de coledocolitiasis, 1 con pancreatitis crónica y 9 casos permanecieron sin filiar la etiología. Hemos realizado 56 punciones: 39 muestras de páncreas en 33 pacientes (fueron diagnósticas en el $81,1 \%$, siendo los diagnósticos más frecuentes el adenocarcinoma y el cistoadenoma seroso), 13 adenopatías y 4 masas abdominales.

Conclusiones: La ecoendoscopia es una técnica con una demanda creciente, presenta escasos riesgos y conlleva una mejor toma de decisiones en un importante número de pacientes con enfermedades diversas. Por lo tanto, su inclusión en la práctica clínica rutinaria ha de ser considerado.

Palabras clave: Ultrasonografía endoscópica (USE). Impacto clínico.
Recibido: 19-11-09.

Aceptado: 30-04-10.

Correspondencia: Elvira Poves Martínez. C/ Santiago de Compostela, 28, 3 D.28034 Madrid.e-mail: epoves.hupa@salud.madrid.org.
Poves E, del-Pozo D, Tabernero S, Bardina A, Martínez P, Castillo MC. Clinical impact of High-Definition Endoscopic Ultrasonography (EUS) in a district hospital. Rev Esp Enferm Dig 2010; 102: 698-703. 


\section{INTRODUCCIÓN}

High-Definition Endoscopic Ultrasonography (EUS) or Endoscopic Ultrasound is a diagnostic method with therapeutic possibilities that comes from the combination of an endoscopic vision system along with an ultrasound transducer located in the distal part in a single endoscope. The combination of both techniques allows studying the mucosa and the wall of the digestive tract and adjacent organs (1). This technique was developed in the 80's mainly to cover the limitations of abdominal ultrasound (2) and today is the only imaging test that displays the different layers of the gut wall in detail and allows the performance of light guided punctures of the digestive tract.

In the last years, different studies that analyze the information and the usefulness of both EUS (1) have been published: staging of esophageal and stomach neoplasms $(4,5)$, study of submucosal lesions of the gastrointestinal tract (6), assessment of portal hypertension, study of gallbladder and bile duct diseases $(7,8)$, study of the mediastinum and, most importantly, the study of the pancreas $(9,10)$. However, there are few publications analyzing the need of this procedure by inhabitants as well as the clinical impact of this new technique in a hospital (11-13) and for this reason, in this paper we analyze all EUS explorations performed in the first 18 months in our hospital.

\section{MATERIALS AND METHODOLOGY}

We have analyzed all EUS explorations performed during the first 18 months in the Gastroenterology Department of a secondary average hospital in Madrid. This Department an area of about 378,000 inhabitants, $83 \%$ of urban population, and provides an allocation of 549 beds, 24,406 discharges and 180,758 primary visits, but not all specialties are include, such as, Thoracic Surgery, Neurosurgery and Cardiac Surgery (14).

The tests analyzed are those scans performed in the first months after the implementation of the technique in the hospital, i.e., including the first tests conducted independently by physicians after a training period. Therefore, they are part of the initiation of a learning curve.

The EUS technique has been performed by Hitachi Ultrasound 5500 and 6500 systems with radial and linear Pentax EG 3670 URK Echoendoscopes.

All examinations performed were prospectively entered in a database, including: age, sex, date of performance, indication, petitioner service, material employed, sedation, procedure, complications and findings.

The scans have been performed on an outpatient basis except those listed inpatients. The average delay for the scan was 10 days.
We have considered idiopathic acute pancreatitis in those cases where after a detailed history, analytical studies, including calcium and triglycerides, ultrasound and abdominal computed tomography (CT) scan were performed and it has not been possible to establish the cause of it.

Chronic pancreatitis is a multifactorial disease and its diagnosis is usually based on clinical and morphological changes described in various imaging tests. EUS is now considered a very sensitive technique for the diagnosis of chronic pancreatitis. Thus a series of criteria described by ultrasonographic changes of both the parenchyma and the ducts are followed. We have considered that the presence of three or more of the criteria is diagnostic of chronic pancreatitis $(15,16)$.

In eligible patients, based on guidelines and results, findings were compared with the anatomical studies of surgical specimens and other imaging studies, such as, CT and Endoscopic Retrograde Cholangiopancreatography (ERCP).

All examinations have been performed with anesthesiologist-controlled sedation except in two patients that they were performed under general anesthesia due to the presence of previous lung disease.

When Fine Needle Aspiration Biopsy (FNA) was performed, an on site pathologist was suitable.

\section{RESULTS}

277 EUS scans have been performed, as well as a therapeutic EUS (treatment success cystogastronomy for pancreatic pseudocyst). Out of the 277 EUS scans performed, 118 were men and 159 women, mean age of 60.5 years (range between 18 and 108).

During the first months, the average was 11 scans per month; such average increased gradually up to 28 scans per month in the last three months. In the first year, 39 scans per 100,000 people were performed compared to the 70 scans per 100,000 inhabitants in the last 6 months.

We collected 2 complications $(0.7 \%)$, both related to sedation: two respiratory arrests, (one of them required endotracheal intubation) but both were discharged from hospital within 24 hours.

The Department of Gastroenterology (with $76 \%$ of tests) is the main petitioner service, (please notice that we are now introducing such technology in the Hospital), followed by General Surgery and Internal Medicine Services.

The reasons for requesting the tests (in some cases more than one) are mainly related to the study of biliary disease $(34.3 \%)$ followed by the study of pancreatic pathology and etiology of acute pancreatitis. Table I shows the main reasons registered for the request. 
Table I. Reasons for requesting EUS

\begin{tabular}{lcc}
\hline Reasons for requesting EUS & No. & $\%$ \\
\hline Assessment of biliary disease & 96 & 34.7 \\
Study of pancreatic disease (chronic pancreatitis, lesion) & 49 & 17.7 \\
Study of idiopathic acute pancreatitis & 32 & 11.6 \\
Other (masses to study, imaging abnormalities, analytics & & \\
$\quad$ abnormalities...) & 31 & 11.2 \\
Study of submucosal tumors & 29 & 10.5 \\
Extended study of digestive tract tumors & 22 & 7.9 \\
Assessment of enlarged lymph nodes & 10 & 3.6 \\
Assessment of portal hypertension & 6 & 2.2 \\
Assessment prior to mucosectomy & 5 & 1.8 \\
\hline
\end{tabular}

Table II. Main diagnoses by EUS

\begin{tabular}{|c|c|}
\hline Main diagnoses & No. \\
\hline Cholelithiasis & 40 \\
\hline Microlithiasis & 32 \\
\hline Gallbladder polyps & 11 \\
\hline Gallbladder hydrops & 4 \\
\hline Choledocholithiasis & 29 \\
\hline Biliopancreatic tumors & 4 \\
\hline Ampuloma & 1 \\
\hline Solid tumor of the pancreas & 20 \\
\hline Solid and cystic tumor of the pancreas & 8 \\
\hline Cystic tumor of the pancreas & 5 \\
\hline Pancreatic pseudocyst & 2 \\
\hline Compatible with a focal pancreatitis & 1 \\
\hline Chronic pancreatitis & 19 \\
\hline Celiac adenopathies & 21 \\
\hline Peripancreatic adenopathies & 14 \\
\hline Mediastinal adenopathies & 11 \\
\hline Perilesional adenopathies & 10 \\
\hline Periaortic adenopathies & 2 \\
\hline Porta hepatis adenopathies & 1 \\
\hline Portal infiltration & 9 \\
\hline Infiltration of superior mesenteric artery & 3 \\
\hline Infiltration of splenic artery/vein & 5 \\
\hline Infiltration of aorta & 1 \\
\hline Infiltration of the aorta & 1 \\
\hline Portal vein thrombosis & 2 \\
\hline Splenic thrombosis & 4 \\
\hline Cavernous tumor of the porta & 2 \\
\hline Esophageal varices & 2 \\
\hline Gastric varices & 4 \\
\hline Esophageal GIST & 5 \\
\hline Tumor of the esophagus/cardia & 5 \\
\hline Gastric cancer & 15 \\
\hline Gastric GIST & 23 \\
\hline Thickened gastric folds & 2 \\
\hline Porta hepatis mass & 1 \\
\hline Polyp esophageal/gastric & 3 \\
\hline Mass of undetermined origin & 4 \\
\hline
\end{tabular}

The main diagnoses are found in table II, where you can see that the pathology of the biliary tract and pancreas are the most frequently observed.

We found no abnormalities in EUS scanning only in 28 patients, this is, $10 \%$ of the scans performed.
EUS scans related to the study of idiopathic acute pancreatitis were performed in 32 patients, who were diagnosed: 20 (63\%) microlithiasis, 2 choledocholithiasis, a 1 with chronic pancreatitis, and 9 without etiology (28\%). The two patients who had a choledocholithiasis have been solved with ERCP, $80 \%$ of patients with microlithiasis have been subjected to cholecystectomy, and after monitoring these patients, with an average of 21.5 months, no one has presented a new episode of acute pancreatitis.

CBD stones were diagnosed in 29 patients (Fig. 1), an ERCP was performed in 27 patients in less than a month and $100 \%$ has confirmed the presence of choledocholithiasis.

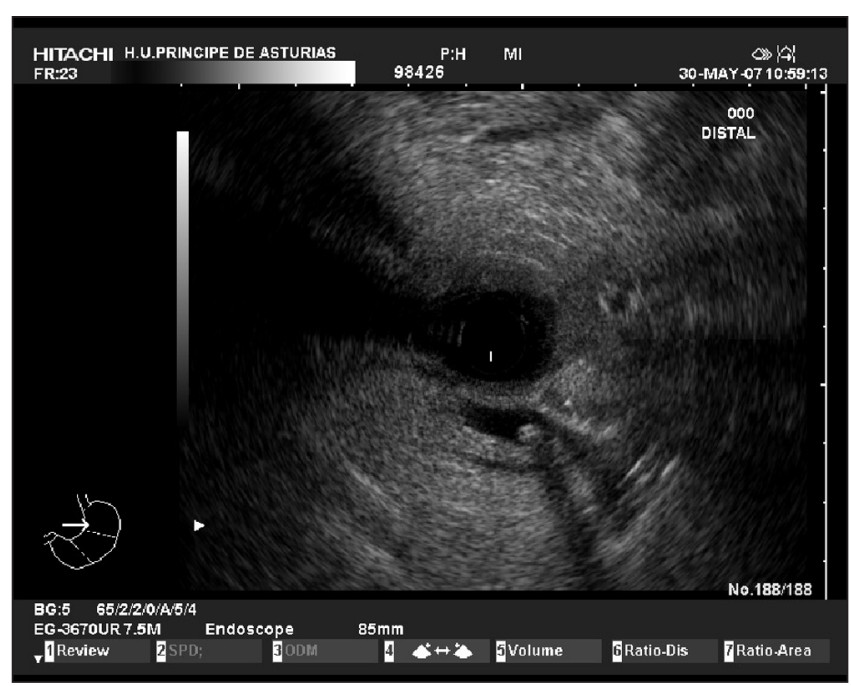

Fig. 1. Choledocholithiasis.

Chronic pancreatitis was diagnosed by the presence of three or more criteria used for diagnosis in 19 patients. All patients have a CT done in less than a month either before or after EUS and only in $15.78 \%$ of the cases the presence of chronic pancreatitis have been diagnosed by this test. All patients diagnosed by $\mathrm{CT}$ scan had pancreatic calcifications.

There have been a total of 56 FNA ( $22 \%$ of tests): 39 of pancreas, 13 of enlarged nodes, and 4 of abdominal masses with no clear organ of origin showed by EUS. The 39 pancreatic FNA were performed for 33 patients, since in some of them, scans had to be repeated due to lack of diagnosis.

FNA confirmed final diagnosis in 27 of the 33 patients with pancreatic FNA, i.e., diagnosis was confirmed in $81.8 \%$ of the patients and $69 \%$ of the FNA cases. Adenocarcinoma was the most common tumor (Fig. 2) followed by serous cystadenoma as shown in table III. All the patients diagnosed by fine-needle aspiration cytology have been followed-up since then, finding a false negative, because a patient diagnosed with chronic pancreatitis, subsequently turned out to have an adenocarcinoma. 


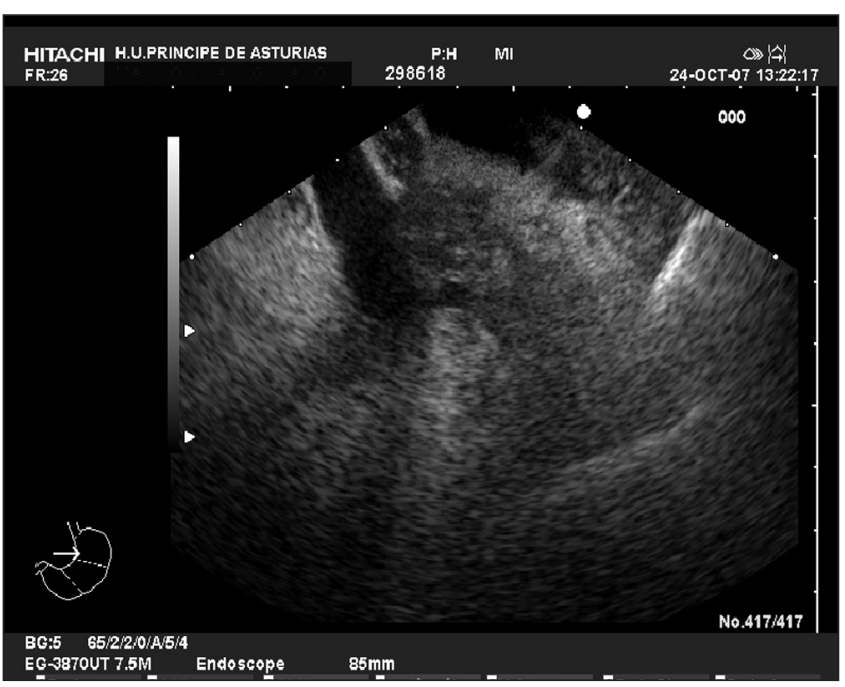

Fig. 2. Pancreatic head adenocarcinoma.

Table III. Diagnosis by EUS-FNA

\begin{tabular}{lc}
\hline Diagnosis by Fine Needle Aspiration Biopsy (FNA) & No. \\
\hline Serous cystadenoma & 5 \\
Mucinous cystadenoma & 3 \\
Mucinous cystadenoma & 1 \\
Intraductal carcinoma & 3 \\
Solid pseudopapillary tumor & 2 \\
Adenocarcinoma & 9 \\
Neuroendocrine tumor & 2 \\
Chronic pancreatitis & 2 \\
Without cytological diagnostic & 6 \\
\hline
\end{tabular}

The 6 patients whose diagnoses were not performed by FNA were:

-Four patients who had a solid mass consistent with neoplasia described by EUS, failing to make the diagnosis by FNA cytology. After surgery, an adenocarcinoma was found on all of them.

-One patient with not well-defined heterogeneous mass at the head of the pancreas. 2 FNA with no cytological diagnosis were performed and subsequent surgery confirmed that this was a chronic pancreatitis.

- One patient diagnosed with uterine leiomyosarcoma with the presence of a solid lesion at the head of pancreas consistent with a metastasis; FNA was insufficient material and a subsequent surgery confirmed the presence of metastasis from a leiomyosarcoma.

FNA has been performed to 13 different nodes in 13 patients: 8 celiac nodes, 3 peripancreatic nodes and two mediastinal nodes. The histologic al diagnoses were: 7 reactive lymphadenopathy, 1 histiocytoma, 1 with malignant neoplastic cells of large tumor cells, 1 lymphoma, 1 neuroendocrine tumor and 2 with insufficient material for diagnosis.

Four bodies diagnosed by EUS, that was not possible to pinpoint to which structure they correspond, underwent FNA and these were the results: 1 adenocarcinoma of the stomach, an inflammatory process of duodenum, 1 colonic duplication cyst and the fourth one corresponds to a mass in hepatic hilum due to a recurrence of a previously operated gastric adenocarcinoma.

\section{DISCUSSION}

EUS is a technique that has being increasingly introduced in different public hospitals, more frequently in larger or important tertiary hospitals, and referral centers. Although this study analyzed the first 18 months after the introduction of the technique in a non referral hospital, we noticed that the need for technology is increasing from about 39 scans per 100,000 inhabitants to 70 scans per 100,000 inhabitants per year. We consider that during the next years the number will be even higher as the technique will be best known, and the spreading of all its potential diagnostic and therapeutic options, not developed yet. These data confirm that it is a necessary technique not only for tertiary hospitals or referral hospitals, but also for the smaller ones where at least 200 annual examinations, depending on the population to be served, would be performed, in order to make profitable its high cost implementation and also to maintain an appropriate level of experience and knowledge $(10,17)$.

As for the safety of EUS concerns, various technical complications have been reported, both related to the technique and the sedation procedure used (18). Complications related to the technique described are esophageal perforation $(0.03 \%)(19,20)$ associated with intubation of the linear endoscope in the presence of esophageal neoplasms and physician endoscopist with less than 1 year of experience. Other complications related to FNA have been described, such as bacteremia, acute pancreatitis (in the range of $0-2 \%$ ), bleeding and bile peritonitis $(21,22)$. The most common complication related to sedation is desaturation with possible respiratory arrest. The two cases we have encountered in our series have been associated with sedation, although it should be noted that it has been controlled by an anesthesiologist and a deep sedation has been established, enabling technology to be performed in good conditions both for the physician and the patient, especially when FNA was required. Despite the complications described, the incidence is very low, so it can be considered a safe technique.

The main pathologies that have been introduced progressively as in other series (13) and that occupy the bulk of the volume of examinations performed are biliopan- 
creatic pathology and management of upper digestive tract tumors.

Biliary pathology in our series represents the largest number of indications, and the highest number of diagnoses. EUS has been shown to be superior to CT scan, abdominal ultrasound and MRI-cholangiography for the diagnosis of choledocholithiasis (23-25) with sensitivities and specificities approaching $100 \%$ primarily under $10 \mathrm{~mm}$ stones. In our area, the access to MRI-cholangiography is limited by significant delays, so EUS has modified sensitive clinical practice so that patients with unknown etiology and clinically suspected biliary disease, undergo EUS before ERCP; i.e. it has almost displaced diagnostic ERCP for biliary disease.

Acute pancreatitis is a disease that can range from mild and self-limited process to severe cases with multiple organ failure and even death; although there are many etiologic causes described as possible, gallstones and alcohol are by far the two most frequent. Understanding and treating the etiologic cause is important to prevent recurrence of pancreatitis. When the cause of acute pancreatitis is gallstones and a suitable treatment isn't established, recurrent acute pancreatitis is $30-70 \%$ within the two to three following years (26). It has already been shown that EUS is very useful in the etiological diagnosis of idiopathic acute pancreatitis $(27,28)$, and it is recommended to perform the scans at least 3-4 weeks after discharge from hospital, in order not to interfere with their assessment with possible pancreatic parenchymal abnormalities related to the acute symptoms $(29,30)$. Out of the 32 examinations performed by idiopathic acute pancreatitis, EUS has allowed to diagnose and treat the causes in $72 \%$ cases, so that management by ERCP and cholecystectomy in biliary etiology has meant that new symptoms were note found during the patient monitoring. These results and the inclusion of EUS in the management of acute pancreatitis have changed our clinical practice so that now EUS is performed in all patients with idiopathic acute pancreatitis four weeks after the discharge of the first episode.

One of the major changes involved in the introduction of EUS is the diagnosis of pancreatic tumors, not always easily distinguishable from chronic pancreatitis. The technique allows not only to identify pancreatic masses, but also to determine whether they are solid or cystic, to analyze the content of the cysts, to analyze cell composition and to stage them $(9,31)$.

In our series, FNA was performed in $22 \%$ of the tests, 39 of them of a pancreatic mass; in $18 \%$ of cases cytological diagnosis could not be reached. For pancreatic adenocarcinoma there is a false diagnosis of chronic pancreatitis and in 4 patients with compatible endoscopic ultrasonography image cytology was not diagnostic, which means that only $67 \%$ of adenocarcinomas have been confirmed by cytology, a figure similar to other series (32). The study also allowed a staging not only by the presence of lymph nodes but mainly by the infiltration of vascular structures. Currently EUS is a technique required in our area for diagnosis and staging of pancreatic masses.

The study of the upper digestive tract tumors has led to $17 \%$ of exploration, of which $58 \%$ were gastrointestinal stromal tumors (GIST). In the case of submucosal tumors it allows the diagnosis and the definition of them: location, size, and criteria of benignity and malignancy of the lesion, thus facilitating decision-making when considering endoscopic and/or surgery treatments (6).

We conclude that EUS is a technique that although it requires some investment for implementation and a substantial learning curve, its demand is steadily increasing and has limited risks; it allows making decisions to improve the clinical management in a significant number of patients with different diseases, so the implementation of EUS in routine clinical practice has to be a reality.

\section{REFERENCES}

1. Súbtil JC, Betés M, Perez N, Muñoz-Navas. Ecoendoscopia digetiva, instrumentación e indicaciones generales. Rev Esp Ecogr Digest 2001; 3: 8-18.

2. DiMangno EP, Buxton JL et al. Ultrasonic endoscopy. Lancet 1980; 22: 629-31.

3. Fernández-Urién I, Súbtil JC, Muñoz-Navas M. Ecoendoscopia. Estado actual. Rev Esp Enferm Dig 2003; 95: 68-80.

4. Fusaroli WE, Wallace MB. Endoscopic Ultrasound and upper gastroeintestinal disorders. J Clin Gastroenterol 2003; 36: 103-10.

5. Mallery S, Van Dam J. EUS in the evaluation of esophageal carcinoma. Gastrointest Endosc 2002; 52: 6-11.

6. Amitabh Chak, MD. EUS in submucosal tumors. Gastrointest Endosc 2002; 56: 43-48.

7. Tse J, Liu L, Barkun AN, et al. EUS: a meta-analysis of test performance in suspected choledocholitiasis. Gastrointest Endosc 2008; 67: 235-44.

8. Chang Kj. States of the art lecture: Endoscopic ultrasound and FNA in pancreatico-biliary tumors. Endoscopy 2006; 38: 56-60.

9. Kaufman AR, Sivak MV. Endoscopic ultrasonography in the differential diagnosis of pancreatic disease. Gastrointest Endosc 1989; 35 : 214

10. Roch T, Lorenz R, Braig C, et al. Endoscopic ultrasound in pancreatic tumor diagnosis. Gastrointestinal Endosocpy 1992; 102: 188.

11. Memoria del 2007. Hospital Universitario Príncipe de Asturias. Comunidad de Madrid.

12. Wallace MB, Hawes RH, Durkalski V, et al. The reliability of EUS form the diagnosis of chonic pancreatitis: interobserver agreement among experienced endosonographer. Gastrointest Endoc 2001; 53: 294-9.

13. Irisawa A, Katakura K, Ohira H, Sato A, Bhutani MS, Hernández $\mathrm{LV}$, et al. Usefulness of endoscopic ultrasound to diagnose the severity of chronic pancreatitis. J. Gatroenterol 2002; 97(supl. XVII): 42.

14. Fockens P, Van de Brande JH, Van dullemen HM et al. Endosonographic T-staging of esophageal carcinoma: a learning curve. Gastrointest Endosc 1996; 44: 58-62.

15. ASGE guideline: complications of EUS. Gastrointest Endosc 2005; 61: 8-12.

16. Eisen GM, Baron TH, Dominitz, et al. Complications of upper GI endoscopy. Gastrointest Endosc 2002;55: 784-93.

17. Das A, SivaK MV, Chak A. Cervical esophageal perforation during 
EUS; a national survery. Gastrointest Endosc 2001; 53: 599-602.

18. ASGE guideline: complications of EUS. Gastrointest Endosc 2005; 61: 8-12.

19. Al-Haddad M, Wallace MB, Woodward TA, et al. The safety of fineneedle aspiration guided by endoscopic ultrasound: a prospective study. Endoscopy 2008; 40: 204-208.

20. Amouyal P, Palazzo L, Amouyal G, et al. Endosongraphy: promising method for diagnosis of extrahepatic cholestasis. Lancet 1989; 2: $1195-8$.

21. BanK S, Indaram A. Causes of acute and recurrent pancreatitis. Gastroenterol Clin North Am 1999; 28: 571-88.

22. Vila JJ, Borda F, Jiménez FJ. Papel de la ecoendoscopia en el estudio etiológico de la pancreatitis aguda idiopática. Rev Esp Enferm
Dig 2008; 100: 90-7

23. Draganov P, Forsmark E. Idiopathic pancreatitis. Gastroenterology 2005; 128: 756-63.

24. Tandon M, Topazian M. Endocopic ultrasound in idiopathic acute pancreatitis. Am J Gatroenterol 2001; 96: 705-9.

25. Yusoff IF, Raymond G, Sahai AV. A prospective comparation of the yield of EUS in primary vs. recurrent idiopathic acute pancreatitis. Gastrointest Endosc 2004; 60: 673-8.

26. Gress F, Savides T, Cummings O, et al. Role of EUS in the preoperative staging of pancreatic cancer: a large single center experience. Gastrointest Endosc 1999; 50: 786.

27. Chhing DC, Jhala D, Jhala N, et al. Endoscopic ultrasound-guided fine-needle Aspiratión biopsy. Cancer 2002; 96: 232-9. 